\title{
INFLUENCE OF PARTIAL LOADING ON THE BEHAVIOUR OF PALLET RACK STRUCTURES
}

\author{
F. Al Qarud ${ }^{1}$, A. Shatnawi ${ }^{1}$, M.S. Abdel-Jaber ${ }^{1}$ and R.G. Beale, ${ }^{2, *}$ \\ ${ }^{1}$ Department of Civil Engineering, University of Jordan, Amman, Jordan \\ ${ }^{2}$ Department of Mechanical Engineering, Wheatley Campus \\ Oxford Brookes University, Oxford, OX33 1HX, UK \\ *(Corresponding author: E-mail: rgbeale@brooks.ac.uk)
}

Received: 11 June 2008; Revised: 19 September 2008; Accepted: 22 September 2008

\begin{abstract}
This paper presents the results of an investigation into the effects of partial loading on the behaviour of steel pallet racks. A six level, six bay, 3-dimensional pallet rack frame model was built using ABAQUS and a geometrically non-linear analysis conducted. Twelve different load combinations were analysed under different boundary conditions and different side imperfections. Most combinations failed by sway buckling. Depending upon the side imperfection and the base condition critical combinations involved having completely unloaded bays or lifts adjacent to two or more fully loaded bays or lifts with reductions in capacity over a fully loaded rack of up to $40 \%$.
\end{abstract}

Keywords: Pallet rack structures, load combinations, pattern loading, semi-rigid connections, non-linear analysis, storage structures

\section{INTRODUCTION}

\subsection{Steel Storage Pallet Rack Systems}

Steel storage pallet racks are widely used throughout the world for storing industrial goods. Moreover these structures provide high storage density. The goods to be stored are generally in cartons or boxes stored on pallets. A typical example is shown in Figure 1.

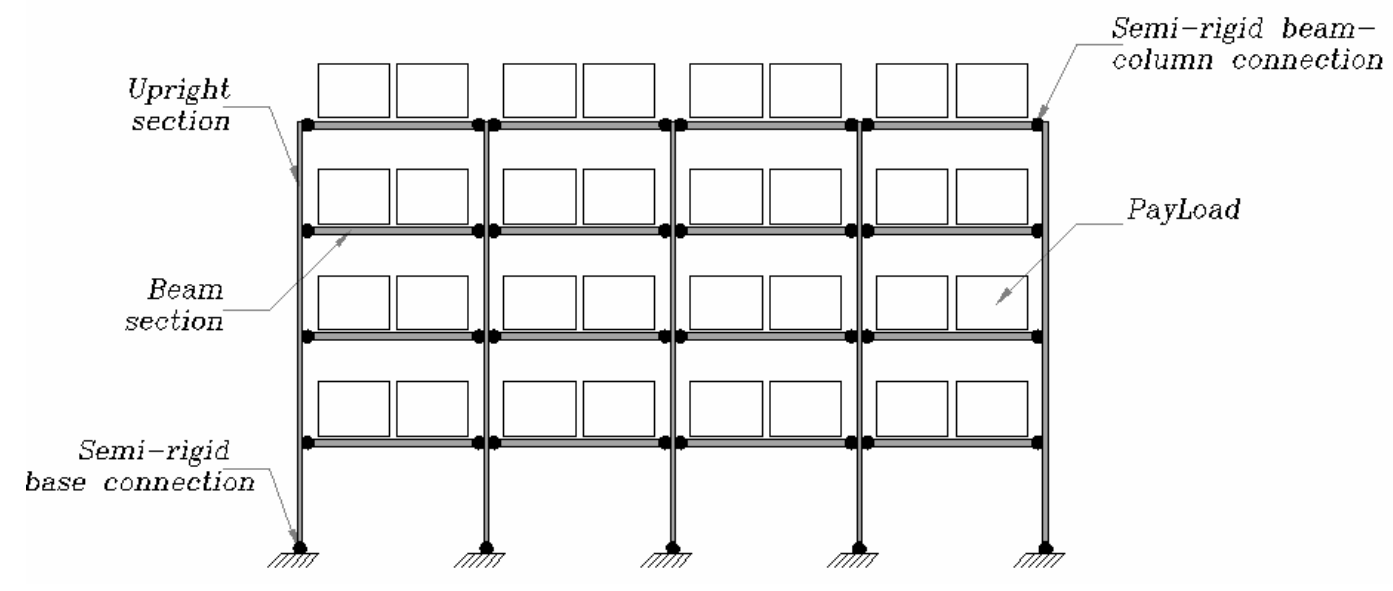

Figure 1. Pallet Rack Structure

Pallet racks are commonly made from cold roll formed steel. Such structures usually have a large number of bays and beam levels. The main components for racking system are vertical supports or uprights, beams, connections and bracing. Uprights are generally thin-walled, perforated open sections with low torsional stiffness. The beams are often thin-walled closed sections with high torsional stiffness. Bracing systems are generally placed in the cross aisle direction. The connections between beams and uprights are semi-rigid and are usually made by the use of tabs and lugs welded onto the ends of beams making a boltless connection into the perforations of the 
uprights [1]. Bolted connections are used to connect the upright with the ground. The base-plate connections can be considered either as semi-rigid or pinned although research by Beale and Godley [2] has shown that under certain combinations of side loads that pinned connections can carry higher loads. Godley [3] has also pointed out that under many load combinations that the difference in performance between semi-rigid and rigid bases can often be considered negligible and that in many cases bases can be considered as either pinned or fixed.

\subsection{Pattern Loading}

A lot of research has been reported on the subject of analyses and design of pallet rack structures, for example [4-9]. However few of these publications have reported the results of pattern loading as is often required by design codes such as Federation Europeene de la Manutention (FEM) code [10] and the Rack Manufacturers Institute (RMI) code [11]. According to the FEM code [10] rack structures may be analysed by considering both down and cross-aisle directions separately as two 2-dimensional frame structures. In addition some of the loads used in the analysis of the rack structure are dead load, imposed loads from stored materials and imperfections in the down and cross-aisle aisle directions. For the design of the upright it is required that both fully loaded and pattern loaded frames shall be shall be considered; these patterns loads are often fully loaded except that a load from a beam near the middle of the structure at the lowest level is removed [12].

Beale and Godley [12-13] developed a program to analyse and design regular pallet racks according to the FEM code. The program determines the buckling load of an equivalent free sway structure and using stability functions, calculates the axial and shear forces and the bending moments within the structure including the non-linear $(F-\Delta)$ effects. The results of the program showed that pattern load effects in combination with imperfections often dominate the failure loads of the analysed racks.

Morz et al [14] and Olsson and Sandberg [15] presented a numerical study with the aim of investigating the influence of removing components from pallet racks, such as horizontal beams or cross-aisle bracing members. Typical cases considered were removing all five pairs of beams at the lowest beam level or having two pairs of beam missing. The results showed that for all these cases of loading the total load-carrying capacity of frame was reduced and the pallet rack failed in a global down-aisle sway mode.

The research reported in this paper investigates the effects on the total load carrying capacity of the frame of different types of pattern loading in combination with different geometrical imperfections. In addition, this study compares frame response under different base conditions - semi-rigid, pinned and fixed.

\section{ANALYSES}

\subsection{Pallet Model}

Steel pallet rack structures are 3-dimensional frame systems. The performance of these structures with fixed-bases under 36-load combinations is compared with similar frames with pinned and semi-rigid bases. In the analyses conducted the vertical and side loads were increased proportionally to determine the maximum loads before failure and the maximum reactions and deflections recorded. The model pallet rack considered in this paper contained 6-levels and 6-bays, the height to first story was $400 \mathrm{~mm}$ as it is common for racking frames to have a low first story, the height of each subsequent story was $1400 \mathrm{~mm}$ and the beam lengths were $2400 \mathrm{~mm}$. Front 
and rear frames were connected by zig-zag bracing, with an initial horizontal member $100 \mathrm{~mm}$ above the ground and with each ' $\mathrm{zig}$ ' of height $850 \mathrm{~mm}$. A horizontal cross-aisle member was at top of the highest 'zig'. The model is shown in Figure 2.

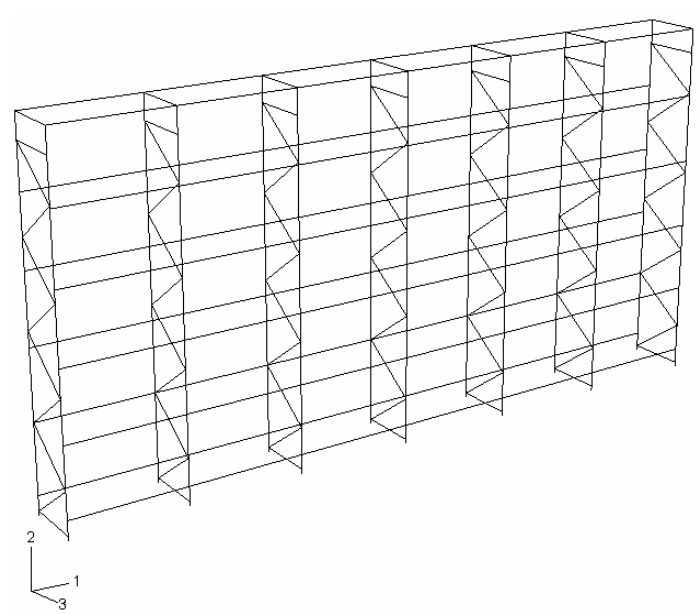

Figure 2. Isometric View of Model

\subsection{Cases of Loading}

36-combinations of loads were analysed and the maximum load that the structure carried determined, the choice of these types of loading was due to the eccentricities caused by imperfections. The cases of loading were considered in this paper are:

- Appling a UDL to all horizontal members (general case).

- Removing the loading on alternate bays for all lifts (case nos.1 and 2)

- Applying checker-board loading by removing loads on alternate bays and columns (case nos. 3 and 4).

- Loading two bays in three (case nos. 5 and 6).

- Removing the loading on alternate levels (case nos. 7 and 8)

- Removing the loading on one bay in the bottom two levels (case nos. 9-12)

- Appling an initial out-of-plumb due to frame imperfections, in down aisle and cross aisle directions.

Figure 3 shows all cases of loading used in the analysis:

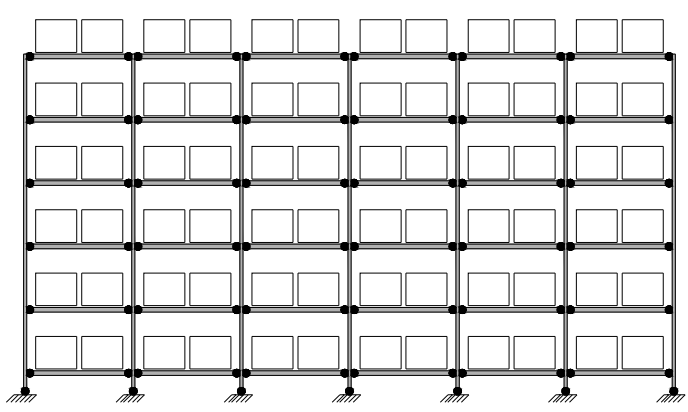

(a) General Case 


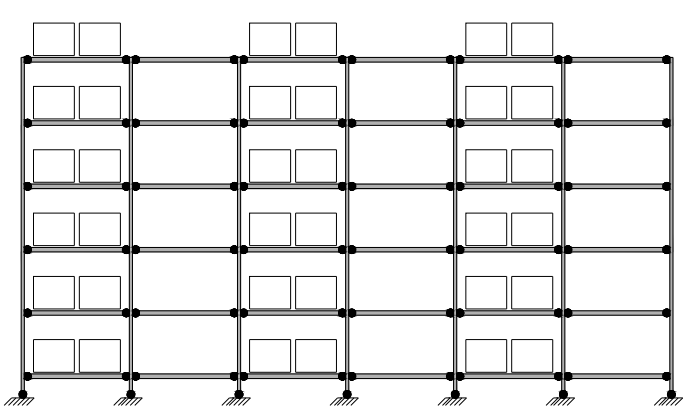

(b) Case 1

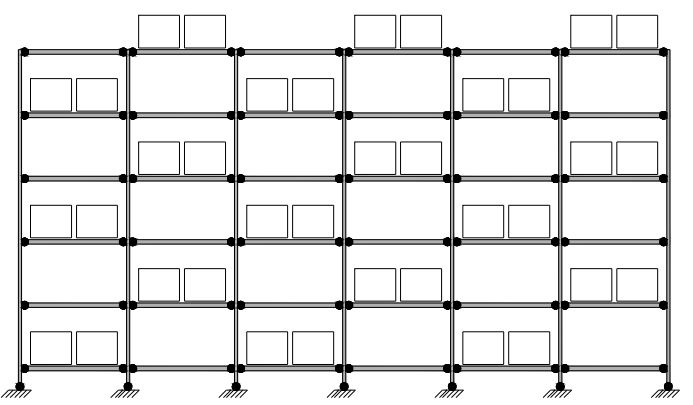

(d) Case 3

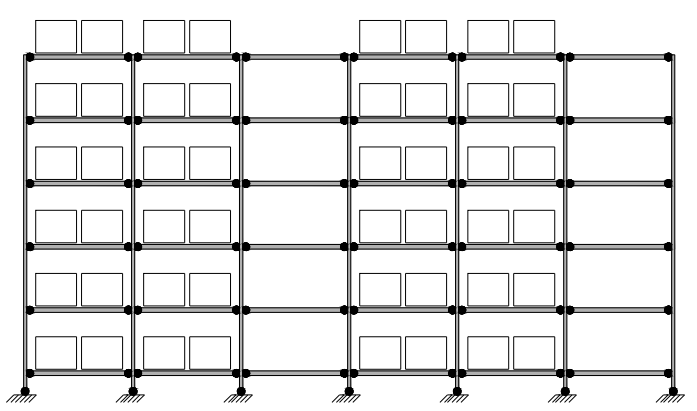

(f) Case 5

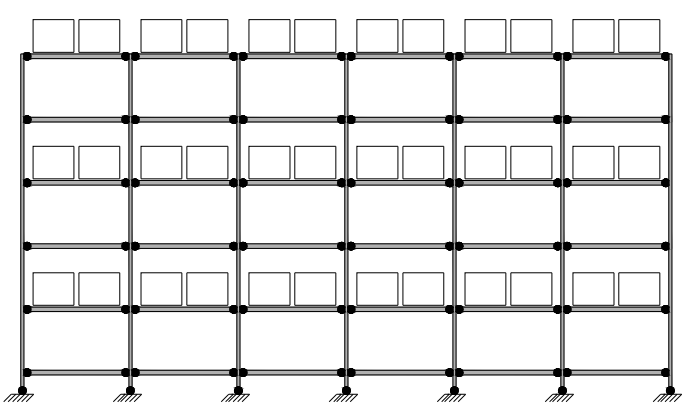

(h) Case 7

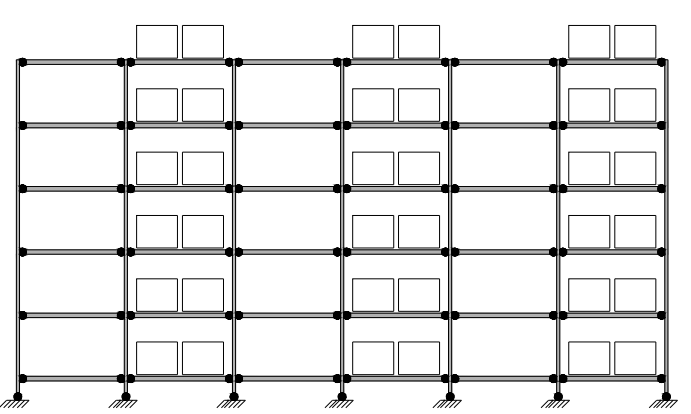

(c) Case 2

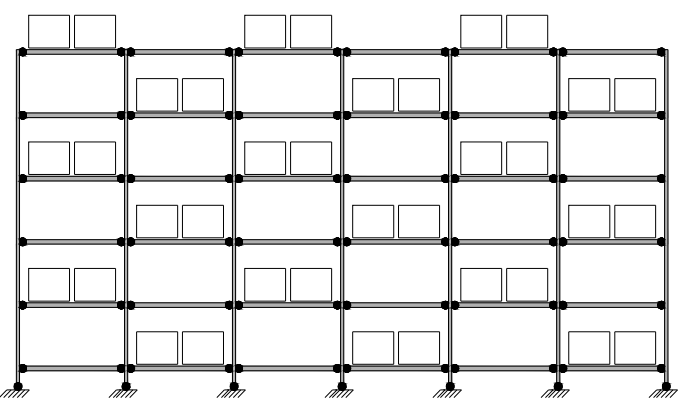

(e) Case 4

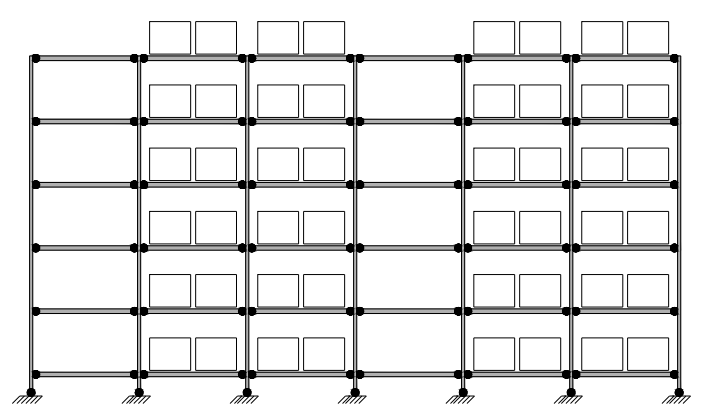

(g) Case 6

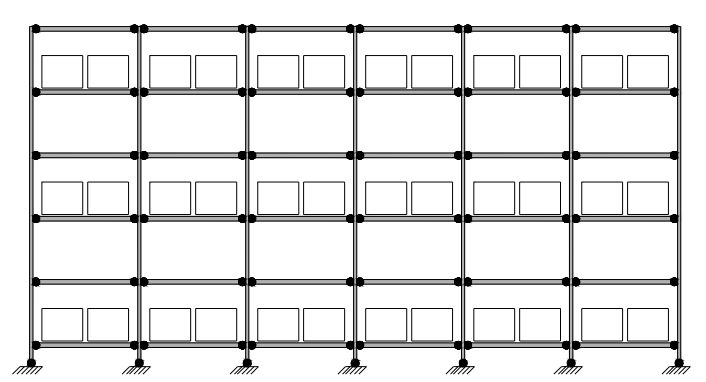

(i) Case 8 


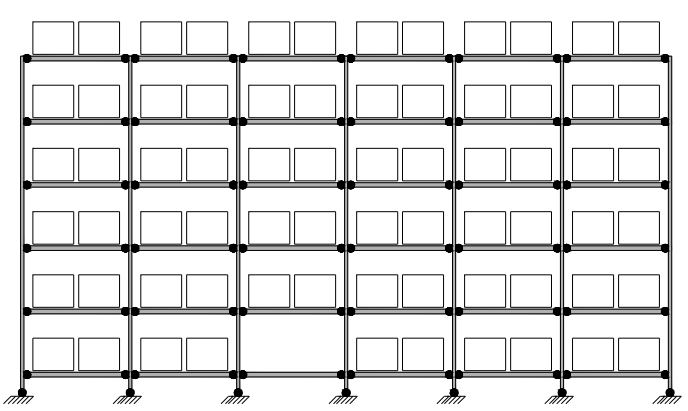

(j) Case 9

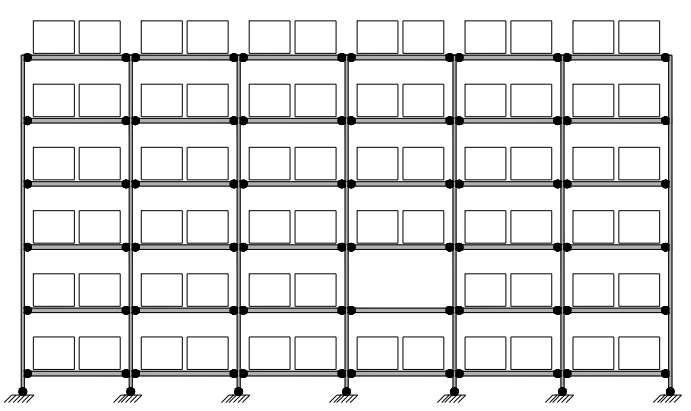

(1) Case 11

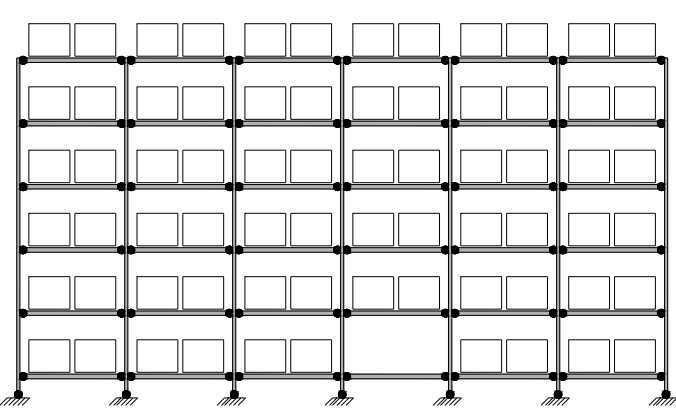

(k) Case 10

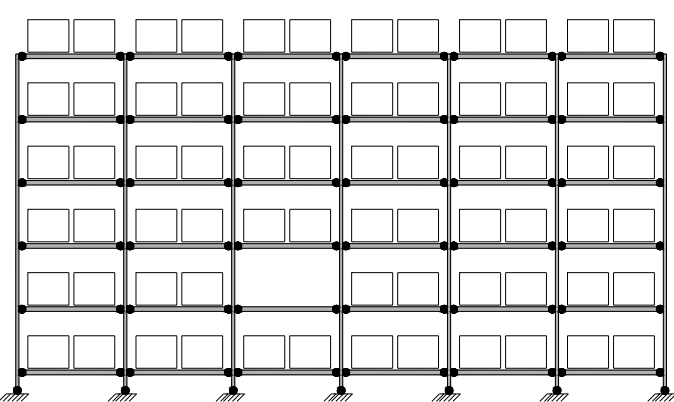

(m) Case 12

Figure 3. Cases of Loading

From the figures it can be seen that without any imperfection that the pairs of load cases are usually mirror images and would give the same results. However, when the geometrical imperfections in the down and cross-aisle directions were added the symmetry was lost and the cases therefore show the effects of the asymmetry.

\subsection{Frame Imperfection}

According to the FEM code [10] the effects of frame imperfections can be considered in the analysis of pallet rack structures by means of an initial out-of-plumb (i.e. initial sway imperfection) or by a closed system of equivalent horizontal forces. In this study the sway imperfections $\phi$ were replaced by a closed system of equivalent horizontal forces. These equivalent horizontal forces were applied at each level and were proportional to the factored vertical loads applied to the structure at the corresponding level as shown in Figure 4.

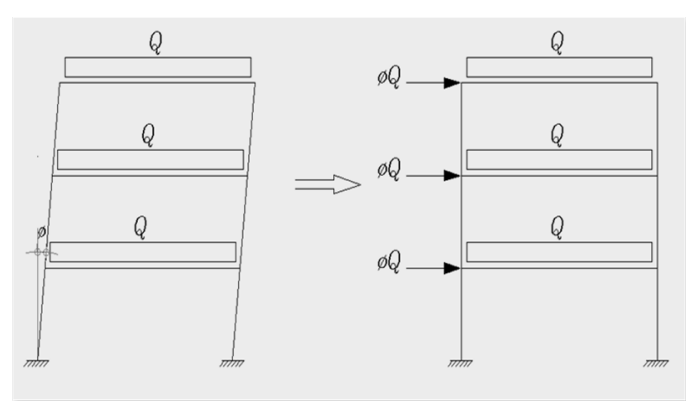

Figure 4. Equivalent Horizontal Forces 
A uniformly distributed load of $1 \mathrm{~N} / \mathrm{m}$ was applied to each beam, and frame imperfections were considered by assigning lateral point loads at each level with a magnitude of $1 \%$ of the applied vertical load.

\subsection{Beam, Upright, Base-plate and Bracing Element and Cross Sections}

The numerical study on the frame was carried out by using a non-linear Finite Element package ABAQUS/CAE [16].

ABAQUS offers a wide range of beam elements and cross sections including "Euler-Brenoulli"-type beams and "Timoshenko" type beams with solid, thin walled closed and thin-walled open sections. The general beam section with Timoshenko-type beam (B31) was selected as the suitable section and element to analyse the beam and upright members.

These elements have two translational degrees and one rotational degree of freedom $\left(\Delta_{x}, \Delta_{y}\right.$ and $\left.\theta_{z}\right)$ at each end and also include the effects of shear flexibility. Each beam member was divided to 24 elements, the bottom upright member was divided into 8 elements and other upright members were divided to 28 elements (the length of each beam element was $100 \mathrm{~mm}$ and the length of each upright element was $50 \mathrm{~mm}$. Typical section values representative of real rack structures were used in the analyses Table 1 show the values used in the analysis.

Table 1. Section Properties

\begin{tabular}{|l|l|l|}
\hline Member & Beams & Uprights \\
\hline Area $\left(\mathrm{mm}^{2}\right)$ & 45.0 & 57.5 \\
\hline Second Moment of Area, down-aisle $\left(\mathrm{mm}^{4}\right)$ & $0.78 * 10^{6}$ & $0.60 * 10^{6}$ \\
\hline $\begin{array}{l}\text { Second Moment of Area, cross-aisle } \\
\left(\mathrm{mm}^{4}\right)\end{array}$ & $0.32 * 10^{6}$ & $0.20 * 10^{6}$ \\
\hline Torsion Constant $\left(\mathrm{mm}^{4}\right)$ & $1.10 * 10^{6}$ & $0.80 * 10^{6}$ \\
\hline Young's Elastic Modulus, N/mm & $210 * 10^{9}$ & $210^{2} 10^{9}$ \\
\hline
\end{tabular}

The members forming the horizontal and diagonal bracing were analysed using truss elements type T3D2 (2-node linear displacement) with cross sectional area $90 \mathrm{~mm}^{2}$, these elements are slender structural members that can transmit only axial force and do not transmit moments. Finally, the base-plate was analysed using shell element type S4R (4-node doubly curved thin shell). The area of this base-plate was taken be $(150 * 150 \mathrm{~mm})$ with a total thickness of $3 \mathrm{~mm}$ and each base-plate was divided into 64-elements. In addition these elements have three translational and three rotational degrees of freedom at each node.

\subsection{Convergence Study}

This convergence study was carried out with the aim of determining the required number of elements that were needed for the finite element model for the beam and shell elements. Moreover for each element type different numbers of element were used and the effect of on the displacements of the models upper node investigated. 


\subsubsection{Beam element}

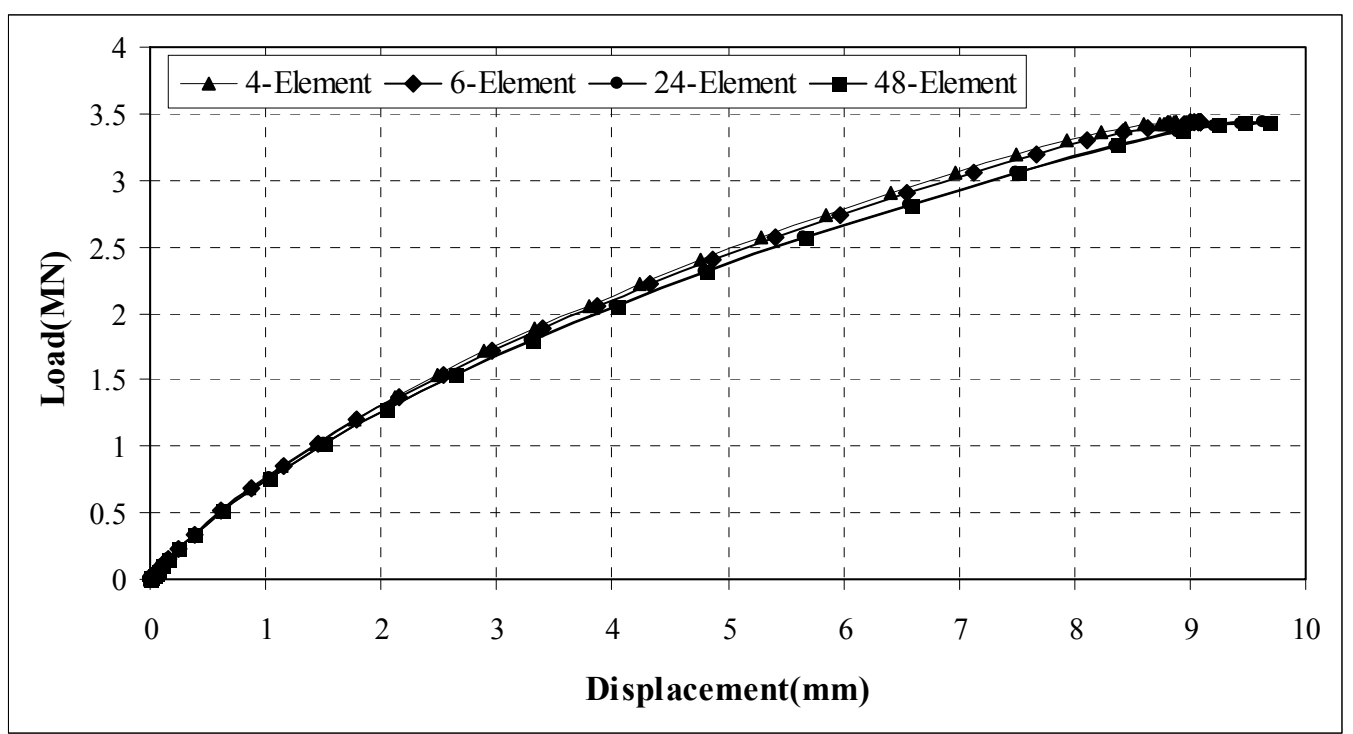

Figure 5. Load-Displacement Curves for Different Number of Elements

Figure 5 shows a plot of the different number of elements $(4,6,24$ and 28-elements) used for the beams. The load-deflection curves are plotted for each number of elements for the general case of a fixed-base with no imperfection.

As the reader can see this figure showed good agreement between the use of 24-elements and 48 -elements for the same frame with a maximum percentage error of $0.01 \%$. Hence the number of elements used in the analysis for all cases was 24 .

\subsubsection{Shell element}

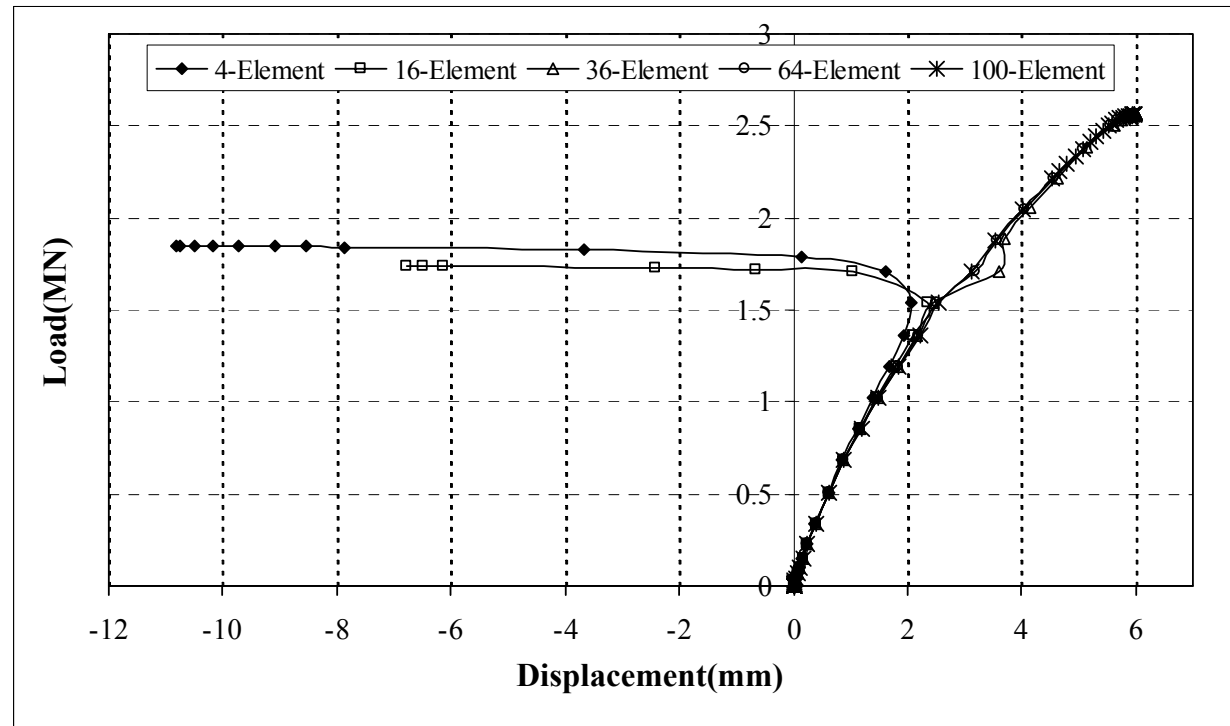

Figure 6. Load-Displacement Curves for Different Numbers of Elements

Figure 6 shows the different number of elements (4, 16, 36, 64 and 100-elements) that were used for shells and the load-deflection curves are plotted for each discretisation for the general case semi-rigid base-plate with no imperfection. 
This figure shows that when 4 and 16-shell elements were used the frame swayed in the negative down-aisle direction and when 36, 64 and 100-shell elements were used the frame swayed in the opposite direction. As no imperfections in either load or geometry occurred in the test model the direction of sway was arbitrary. In addition the use of 36, 64 and 100-shell elements gave a good agreement between them with a maximum percentage error of $0.007 \%$. So this means that finer meshes help to obtain accurate results. It was found that discretising the base-plate to 64-elements gave sufficient, accurate results.

\subsection{Semi-rigid Connections}

Semi-rigid connections were used to connect uprights and beams, and uprights and base-plates. Modelling the semi-rigid connection between the uprights and beams and uprights and base-plates required the use of the spring joint element that represents the required stiffnesses, the ABAQUS SPRING2 element was used. The joint element used to model the beam-upright connection had three translational and three rotational degrees of freedom at each end. The translational stiffnesses of the connection were taken to be infinite. The rotation stiffness about an axis along a cross-aisle direction $\left(z\right.$-axis) was taken to be $0.15 * 10^{6} \mathrm{kNmm} / \mathrm{rad}$. The rotation stiffness about a vertical axis $(y$-axis) was assumed to be zero, and about an axis lying along the beam $(x$-axis) was taken to be infinite.

The joint element used to model the upright-base plate connection such upright-beam connection had three translational and three rotational degrees of freedom at each end. The translational stiffnesses of the connection were taken to be infinite. The rotation stiffness about axis along a cross-aisle direction $\left(z\right.$-axis) was taken to be $0.15 * 10^{6} \mathrm{kNmm} / \mathrm{rad}$. The rotation stiffness about a vertical axis $(y$-axis) was taken to be infinite, and about an axis lying along the beam $\left(x\right.$-axis) was taken to be $0.30 * 10^{6} \mathrm{kNmm} / \mathrm{rad}$.

\section{ANALYSIS AND DISCUSSION}

For each load case a static analysis was conducted followed by non-linear geometric analysis to obtain the maximum load.

\subsection{Without Initial Imperfection Cases}

Figures 7(a), 7(b) and 7(c) show the effects of different base conditions on the displacements of the model's upper left node under different combinations. From Figures 7(a) and 7(c) frames with fixed and pinned bases reached their maximum capacity when they were partially loaded under load case 8. The frame with a semi-rigid base-plate reached its maximum capacity when it was fully loaded (general case) and with no imperfection. The maximum reduction from the fully loaded case was $47 \%$. The effects of small imperfections on the maximum capacity can be clearly seen. The full details of maximum loads in each load case compared against the fully loaded case are given in tables 2-4. The percentage increases/reductions in capacity are compared against the fully loaded case for each imperfection condition. 


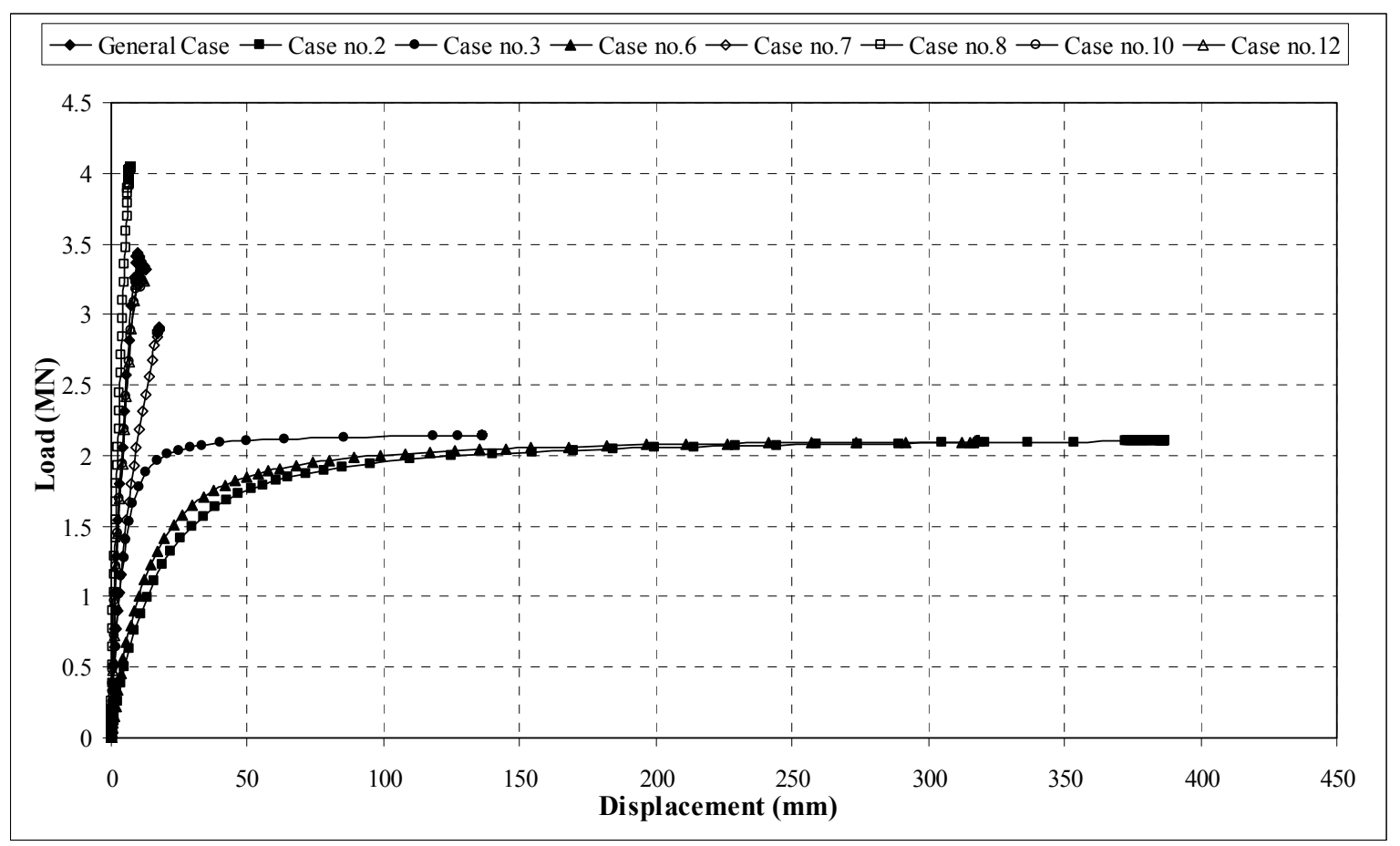

(a) Rigid Base

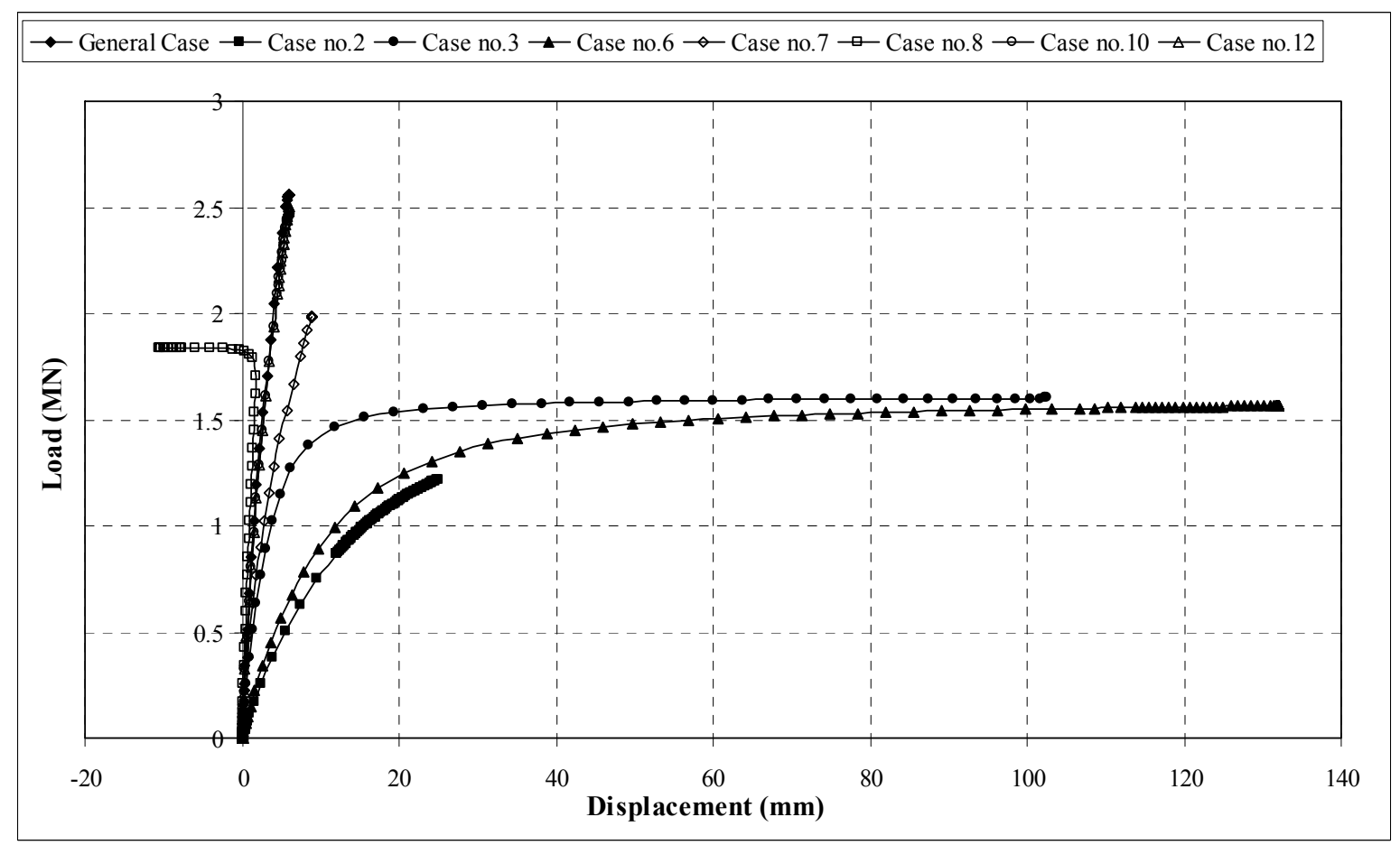

(b) Semi-rigid Base 


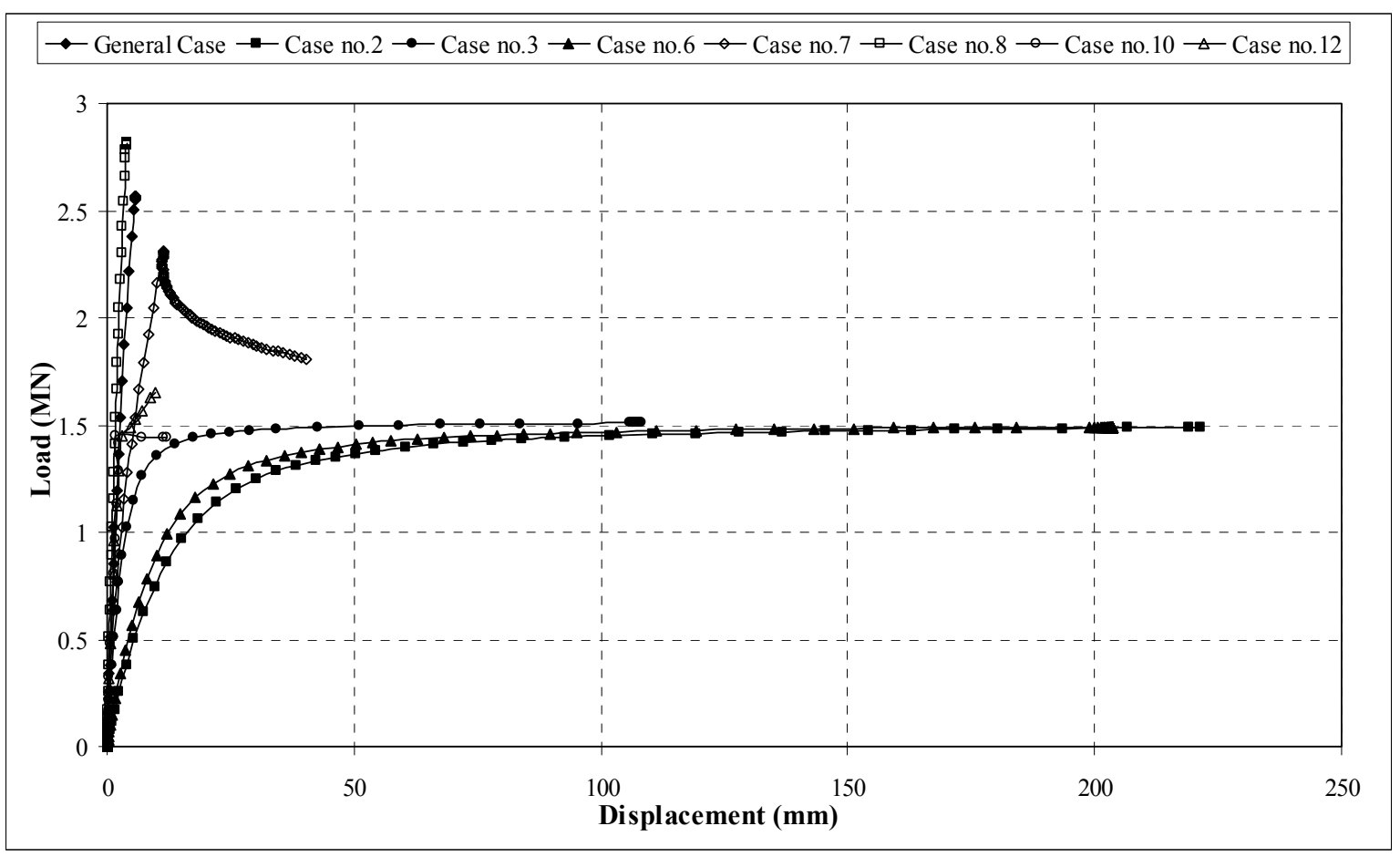

(c) Pinned Base

Figure 7. Load-Displacement Curves for All Cases

Table 2. Influence of Cases of Loading on the Rigid-base Frame

\begin{tabular}{|c|c|c|c|c|c|c|}
\hline \multirow{2}{*}{ Load case } & \multicolumn{6}{|c|}{ Maximum load-capacity of the frame $(\mathrm{kN})$} \\
\hline & \multicolumn{2}{|c|}{ without out of plumb } & \multicolumn{2}{|c|}{ With $1 \% x$-direction } & \multicolumn{2}{|c|}{ With $1 \%(x+z)$-directior } \\
\hline General case & 3432.1 & & 2105.9 & & 2082.4 & \\
\hline Case No.1 & 2099.1 & $-38.8 \%$ & 2123.9 & $0.9 \%$ & 2109.8 & $1.3 \%$ \\
\hline Case No.2 & 2099.2 & $-38.83 \%$ & 2064.0 & $-2.0 \%$ & 2051.0 & $-1.5 \%$ \\
\hline Case No.3 & 2136.9 & $-37.7 \%$ & 2091.0 & $-0.7 \%$ & 2074.6 & $-0.4 \%$ \\
\hline Case No.4 & 2137.2 & $-37.7 \%$ & 2099.2 & $-0.3 \%$ & 2083.0 & $0.0 \%$ \\
\hline Case No.5 & 2097.7 & $-38.9 \%$ & 2103.9 & $-0.1 \%$ & 2089.0 & $0.3 \%$ \\
\hline Case No.6 & 2098.1 & $-38.9 \%$ & 2060.8 & $-2.1 \%$ & 2042.8 & $-1.9 \%$ \\
\hline Case No.7 & 2904.6 & $-15.4 \%$ & 1830.0 & $-13.1 \%$ & 1822.8 & $-12.5 \%$ \\
\hline Case No.8 & 4047.3 & $17.9 \%$ & 2415.9 & $14.7 \%$ & 2401.7 & $15.3 \%$ \\
\hline Case No.9 & 3244.2 & $-5.5 \%$ & 1982.6 & $-5.9 \%$ & 1967.0 & $-5.5 \%$ \\
\hline Case No.10 & 3244.3 & $-5.5 \%$ & 1982.6 & $-5.9 \%$ & 1967.0 & $-5.5 \%$ \\
\hline Case No.11 & 3290.5 & $-4.1 \%$ & 2000.9 & $-5.0 \%$ & 1985.3 & $-4.7 \%$ \\
\hline Case No.12 & 3290.9 & $-4.1 \%$ & 2000.7 & $-5.0 \%$ & 1985.1 & $-4.7 \%$ \\
\hline
\end{tabular}


Table 3. Influence of Cases of Loading on the Semi-rigid-base Frame

\begin{tabular}{||l|ll|ll|ll||}
\hline \multirow{2}{*}{ Load case } & \multicolumn{5}{|l|}{ Maximum load-capacity of the frame (N) } \\
\cline { 2 - 8 } & \multicolumn{2}{|l|}{ without out of plumb } & \multicolumn{2}{l||}{ With 1\% -direction } & \multicolumn{2}{l||}{ With 1\% $(x+z)$-direction } \\
\hline \hline General case & 2560.2 & & 1545.7 & & 1524.1 & \\
\hline Case No.1 & 1570.5 & $-38.7 \%$ & 1475.9 & $-4.5 \%$ & 1480.4 & $-2.9 \%$ \\
\hline Case No.2 & 1568.8 & $-38.73 \%$ & 1467.5 & $-5.1 \%$ & 1477.6 & $-3.0 \%$ \\
\hline Case No.3 & 1601.1 & $-37.5 \%$ & 1490.9 & $-3.5 \%$ & 1463.3 & $-4.0 \%$ \\
\hline Case No.4 & 1600.8 & $-37.5 \%$ & 1499.6 & $-3.0 \%$ & 1475.4 & $-3.2 \%$ \\
\hline Case No.5 & 1578.8 & $-38.3 \%$ & 1510.8 & $-2.3 \%$ & 1477.3 & $-3.1 \%$ \\
\hline Case No.6 & 1564.4 & $-38.9 \%$ & 1502.4 & $-2.8 \%$ & 1472.7 & $-3.4 \%$ \\
\hline Case No.7 & 1988.3 & $-22.3 \%$ & 1348.9 & $-12.7 \%$ & 1306.9 & $-14.3 \%$ \\
\hline Case No.8 & 1840.1 & $-28.1 \%$ & 1701.0 & $10.0 \%$ & 1650.7 & $8.3 \%$ \\
\hline Case No.9 & 2459.6 & $-3.9 \%$ & 1462.9 & $-5.4 \%$ & 1441.2 & $-5.4 \%$ \\
\hline Case No.10 & 2458.6 & $-4.0 \%$ & 1461.0 & $-5.5 \%$ & 1438.0 & $-5.7 \%$ \\
\hline Case No.11 & 2504.5 & $-2.2 \%$ & 1488.2 & $-3.7 \%$ & 1466.8 & $-3.8 \%$ \\
\hline Case No.12 & 2504.3 & $-2.2 \%$ & 1488.1 & $-3.7 \%$ & 1466.8 & $-3.8 \%$ \\
\hline \hline
\end{tabular}

Table 4. Influence of Cases of Loading on the Pinned-base Frame

\begin{tabular}{|c|c|c|c|c|c|c|}
\hline \multirow{2}{*}{ Load case } & \multicolumn{6}{|c|}{ Maximum load-capacity of the frame $(\mathrm{kN})$} \\
\hline & \multicolumn{2}{|c|}{ without out of plumb } & \multicolumn{2}{|c|}{ With $1 \% x$-direction } & \multicolumn{2}{|c|}{ With $1 \%(x+z)$-direction } \\
\hline General case & 2563.0 & & 1470.4 & & 1454.1 & \\
\hline Case No.1 & 1487.9 & $-41.9 \%$ & 1482.3 & $0.8 \%$ & 1466.6 & $0.9 \%$ \\
\hline Case No.2 & 1488.1 & $-41.94 \%$ & 1455.1 & $-1.0 \%$ & 1438.2 & $-1.1 \%$ \\
\hline Case No.3 & 1509.3 & $-41.1 \%$ & 1467.6 & $-0.2 \%$ & 1451.3 & $-0.2 \%$ \\
\hline Case No.4 & 1550.6 & $-39.5 \%$ & 1473.1 & $0.2 \%$ & 1457.1 & $0.2 \%$ \\
\hline Case No.5 & 1534.0 & $-40.1 \%$ & 1476.6 & $0.4 \%$ & 1459.9 & $0.4 \%$ \\
\hline Case No.6 & 1491.3 & $-41.8 \%$ & 1455.4 & $-1.0 \%$ & 1438.5 & $-1.1 \%$ \\
\hline Case No.7 & 2311.3 & $-9.8 \%$ & 1289.8 & $-12.3 \%$ & 1285.0 & $-11.6 \%$ \\
\hline Case No.8 & 2813.1 & $9.8 \%$ & 1685.4 & $14.6 \%$ & 1668.6 & $14.8 \%$ \\
\hline Case No.9 & 1450.4 & $-43.4 \%$ & 1395.0 & $-5.1 \%$ & 1379.5 & $-5.1 \%$ \\
\hline Case No.10 & 1450.8 & $-43.4 \%$ & 1395.0 & $-5.1 \%$ & 1379.5 & $-5.1 \%$ \\
\hline Case No.11 & 1448.9 & $-43.5 \%$ & 1419.7 & $-3.4 \%$ & 1403.5 & $-3.5 \%$ \\
\hline Case No.12 & 1465.0 & $-42.8 \%$ & 1419.4 & $-3.5 \%$ & 1403.4 & $-3.5 \%$ \\
\hline
\end{tabular}


Figure 8 shows the total reaction force in the columns calculated by the summation of reaction force in all columns; these values show good agreement with the total load capacity for each cases of loading. In addition Figure 6 shows the collapse mode for the critical case (case 2).

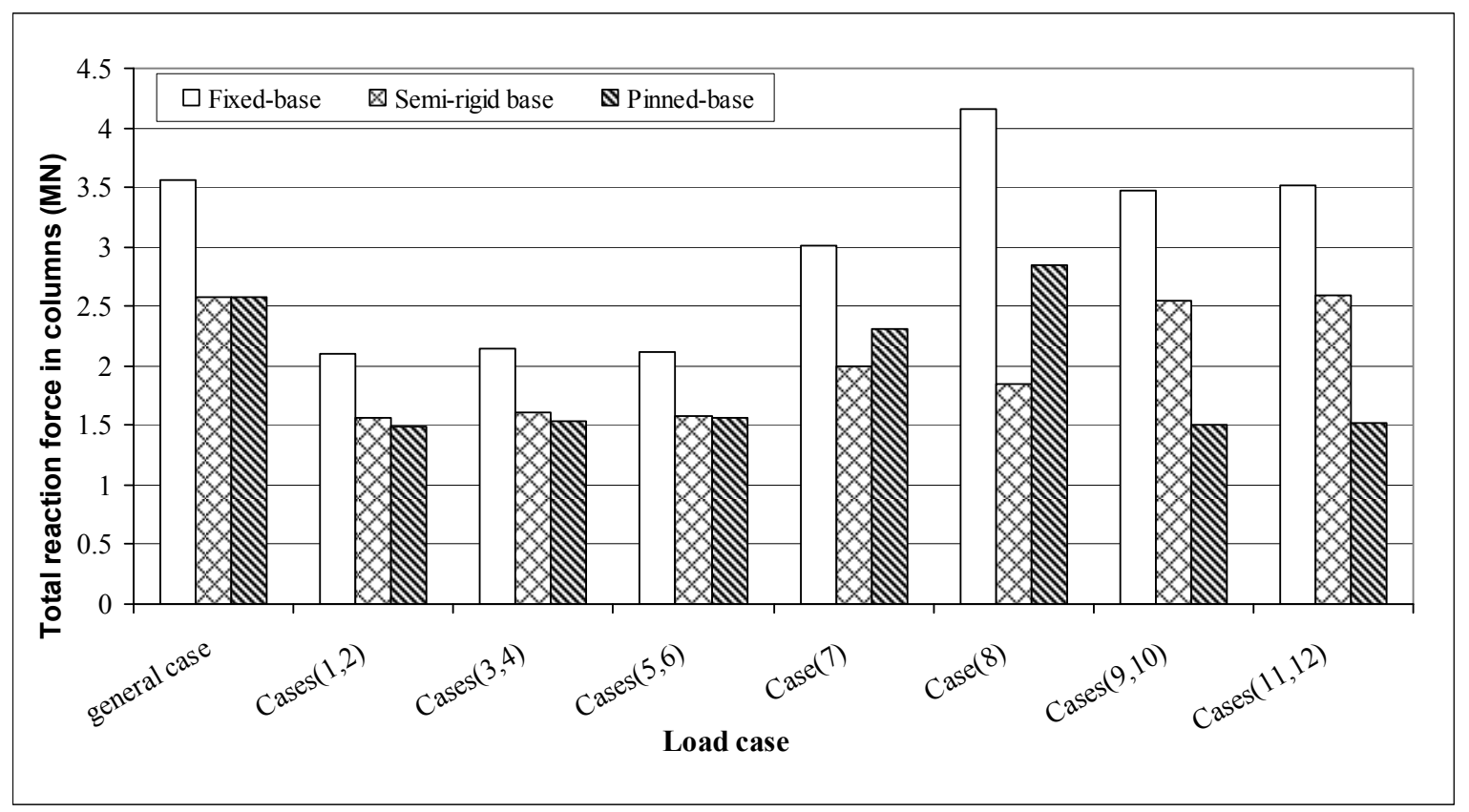

Figure 8. Total Reaction Force in Columns for All Cases with No Imperfection

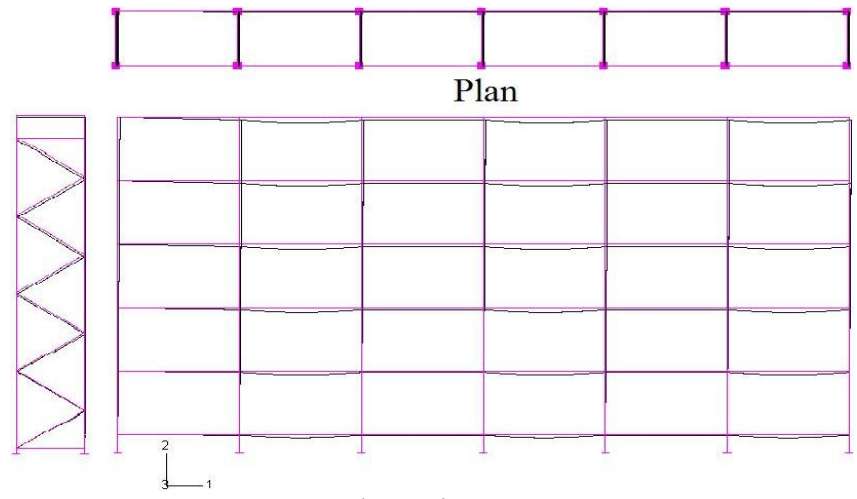

Front elevation

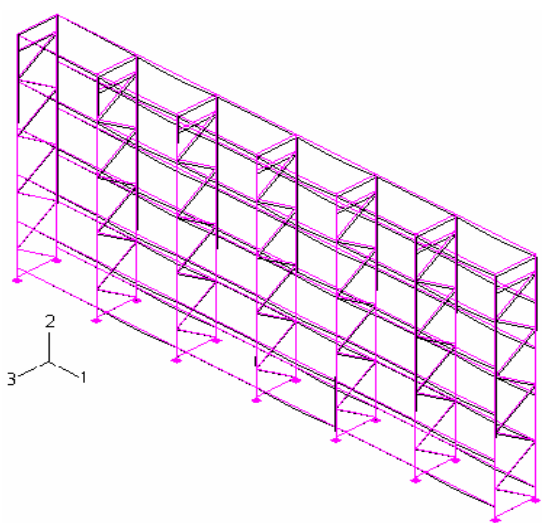

Isometric view

Figure 9. Collapse Mode for Case 2 (Semi-rigid Base-plate Frame)

\subsection{Imperfection in Down and Cross-aisle Directions}

Figures 10(a), 10(b) and 10(c) show the reductions in capacities of the frames when subjected to geometrical imperfections for the same node as used in Figure 7. These figures show 7-different combinations of loading in addition to the general fully loaded case for (rigid, semi-rigid and pinned bases respectively).

As can be seen in figures 10(a), 10(b) and 10(c) and Tables 2-4, the frames reached their maximum capacity when they were partially loaded, normally case 8 . The minimum capacity, below that of the loaded frame was usually either case 11 or case 12 which has one element in the lowest bay unloaded in conformance with the common loadings used in design (see Beale and Godley [10, 11]. 


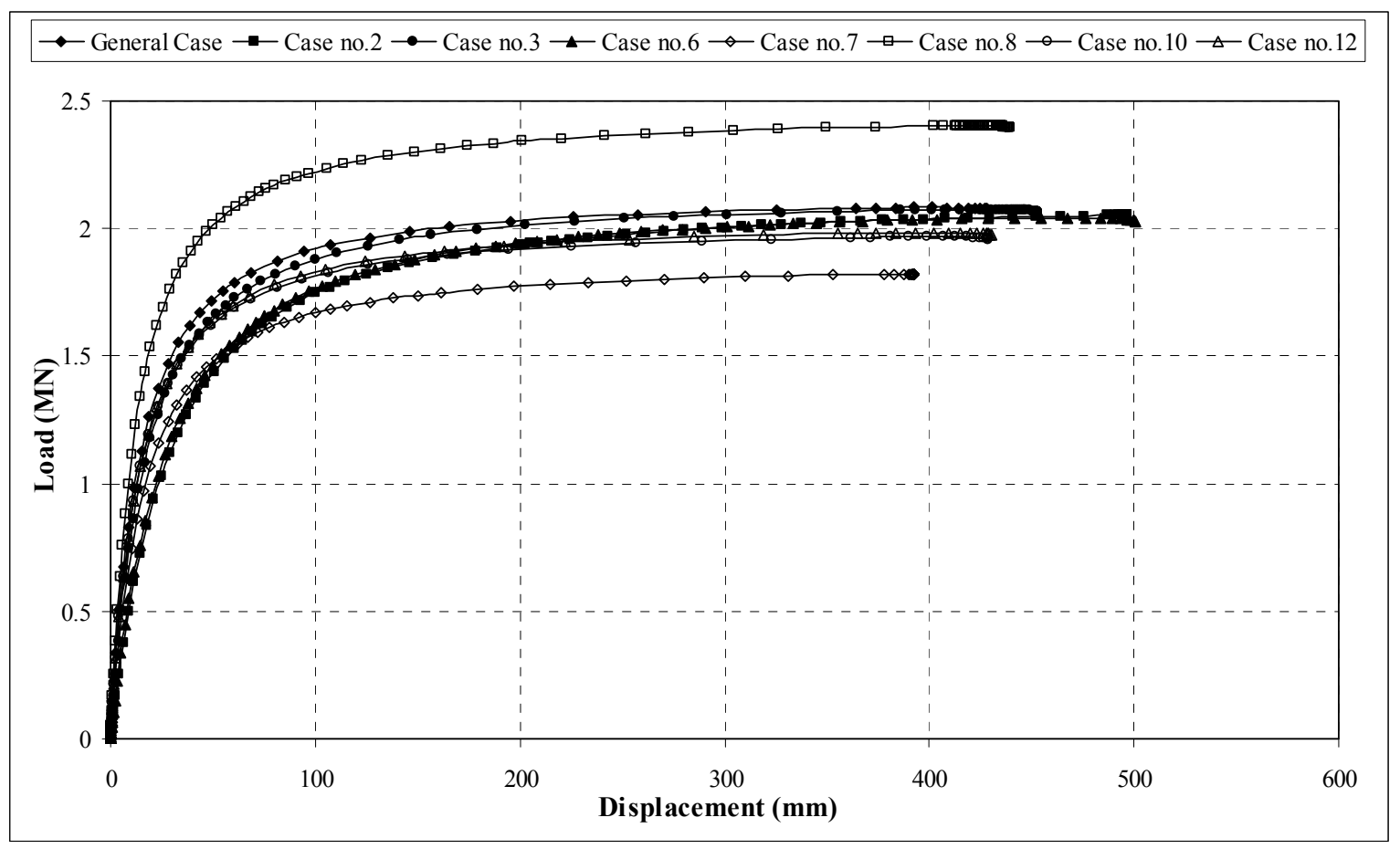

(a) Rigid Base

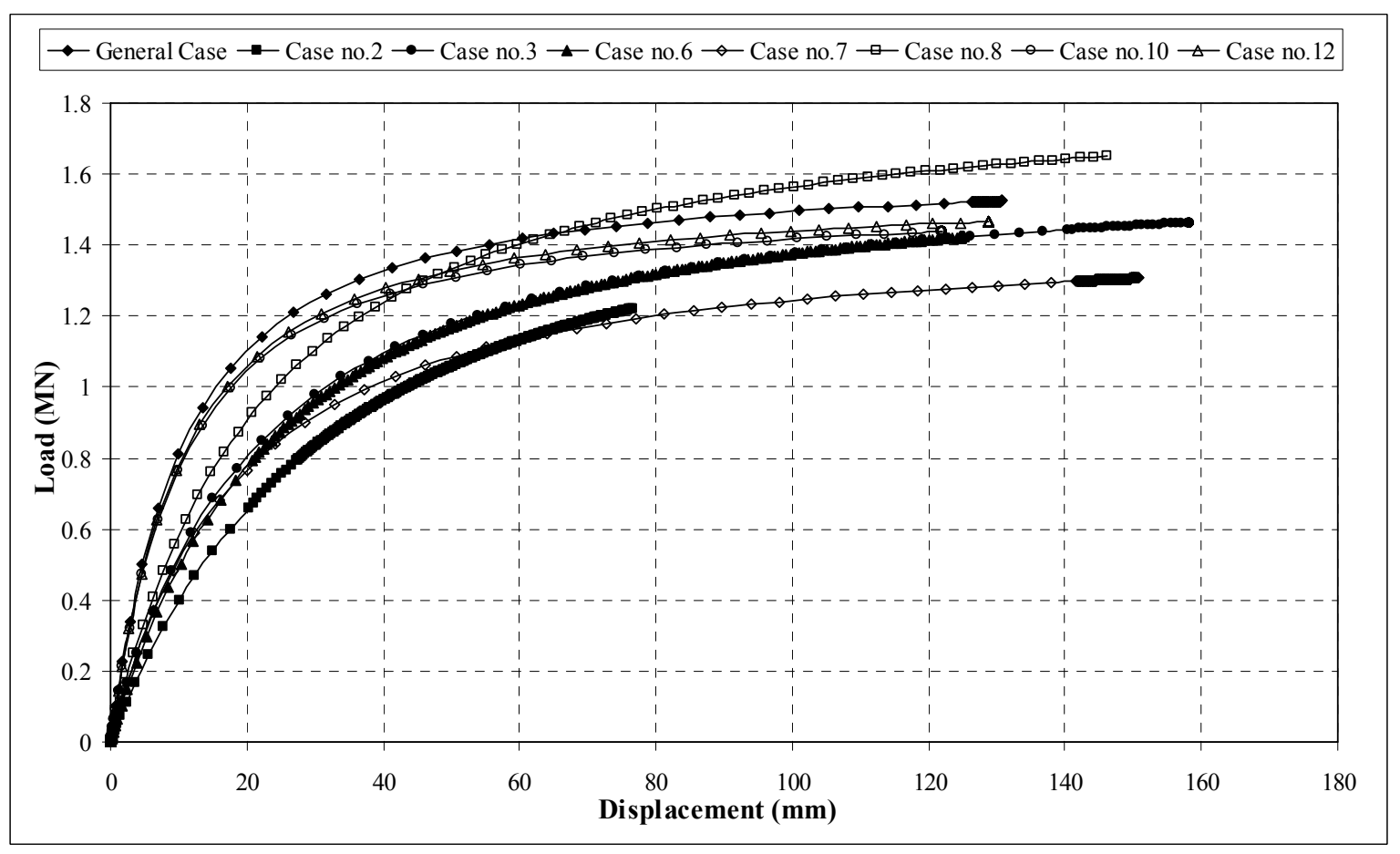

(b) Semi-rigid Base-plate 


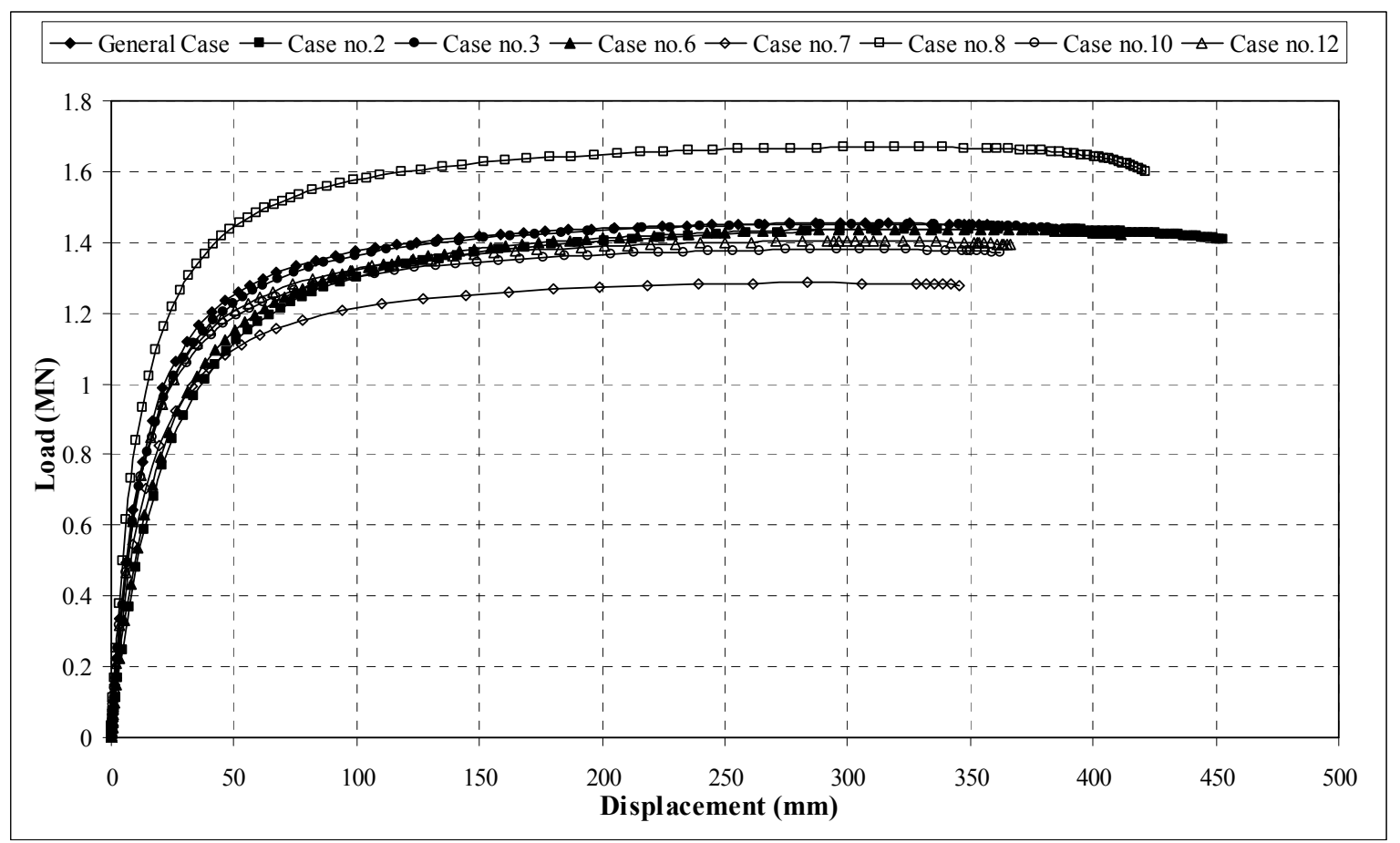

(c) Pinned Base

Figure 10. Load-Displacement Curves for All Cases with Side Imperfection

Figures 11 shows the total reaction force in the columns calculated by the summation of reaction force in all columns; these values have shown good agreement with total load capacity for each cases of loading. In addition Figure 8 shows the collapse mode for the case 7 .

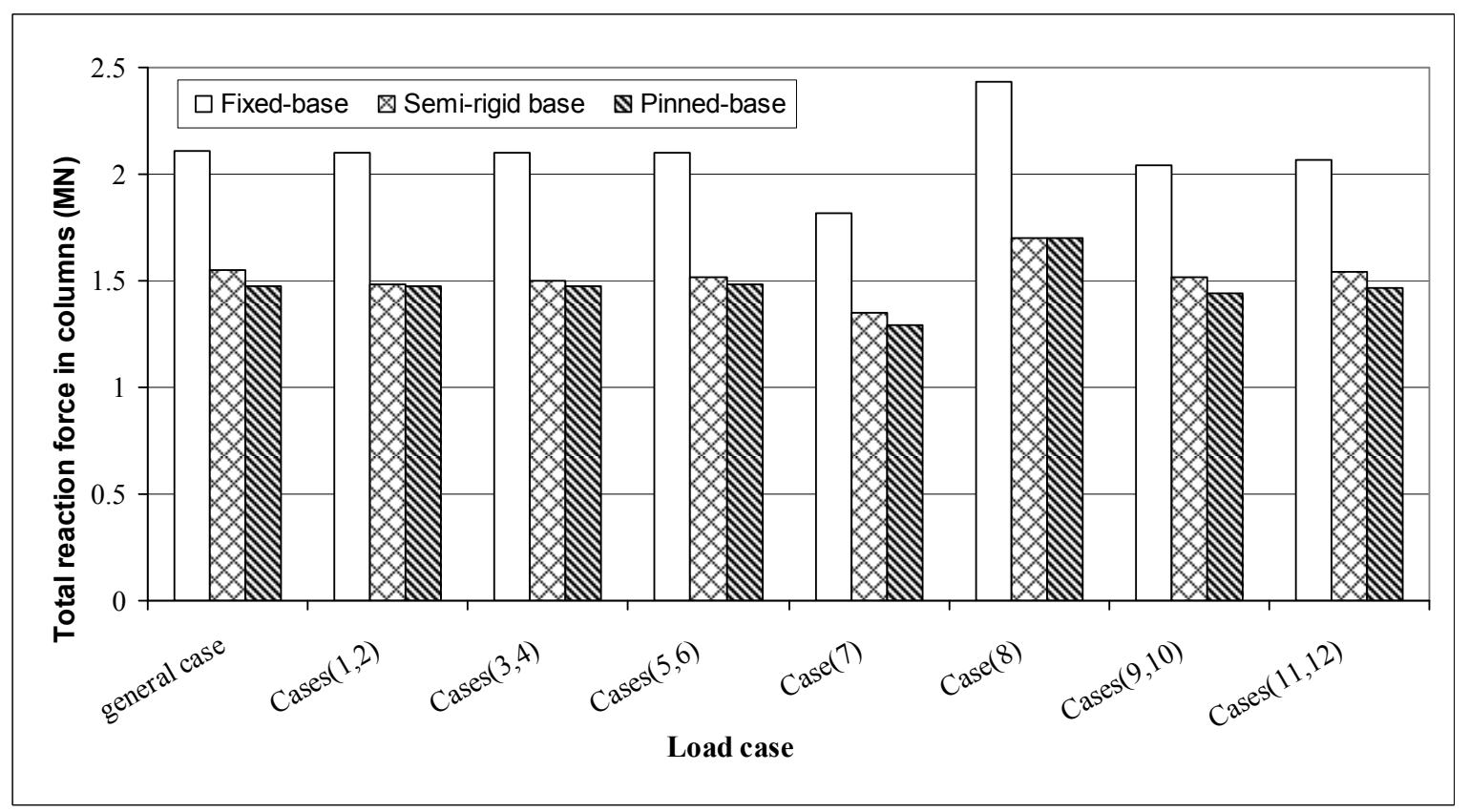

Figure 11. Total Reaction in Columns for All Cases with $1 \%(x+z)$-direction 


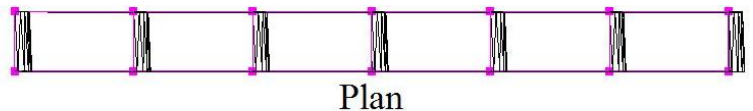

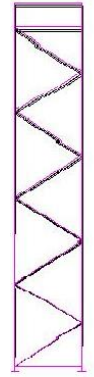

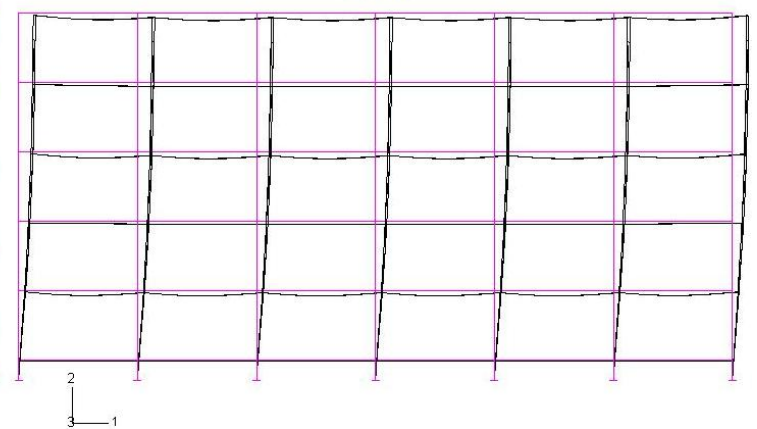

Front elevation

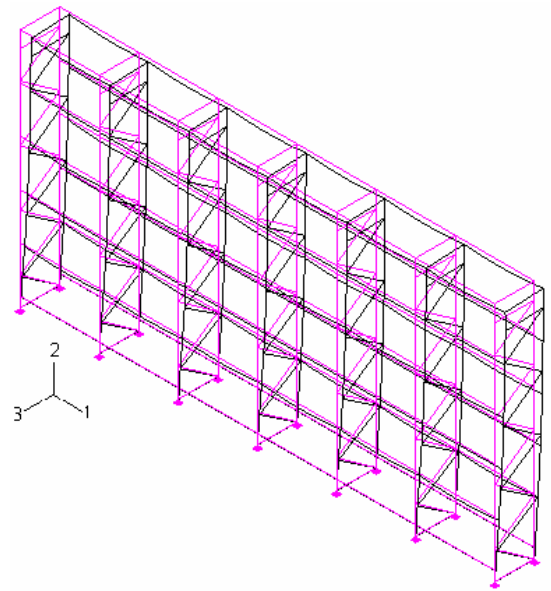

Isometric view

Figure 12. Collapse Mode for Case 7 (Semi-rigid Base-plate Frame)

In all cases analysed the effects of imperfections in reducing the maximum load carrying capacity of frames are clearly seen. Whether the imperfections are caused by geometric imperfection or load asymmetry the frames capacity is reduced by up to $50 \%$ of the fully loaded perfect frame. In addition, the load deflection plots show that the failure in the perfect frame is by structural instability with a steep descending curve.

\section{CONCLUSIONS}

In the present study, the non-linear static responses of pallet racks with fixed-bases, semi-rigid bases or pinned-bases with and without initial imperfections have been investigated under different cases of loading. The study found that the frame's behaviour is affected by partial loads and by lateral loads representing initial imperfections. When a comparison was carried out between all cases with no imperfection it was found that the most critical type loading occurred when the loads were removed on one bay for all lifts but when imperfections in down and cross-aisle directions are present the most critical loading occurs when the loads are removed from one level. In all cases of loading the pallet rack structure failed in a global sway mode except the fully loaded case without imperfections.

\section{REFERENCES}

[1] Markazi, F.D., Godley, M.H.R. and Beale, R.G., "Experimental Analysis of Semi-Rigid Boltless connections", Thin Walled Structures, 1997, Vol. 27, No. 1, pp. 53-87.

[2] Beale, R.G. and Godley, M.H.R. "Problems Arising with Pallet Rack Semi-rigid Base-plates", Proceedings of the First International Conference on Steel and Composite Structures, Pusan, pp. 699-706.

[3] Godley, M.H.R. "The Behaviour of Storage Racking Baseplates", Proceedings of the Sixth International Conference on Steel and Aluminium Structures (ICSAS'07), 2007, Oxford, pp.433-440.

[4] Baldassino, N. and Bernuzzi, C., "Analysis and Behaviour of Steel Storage Pallet Racks", Thin-Walled Structures, 2000, Vol. 37, pp. 277-304.

[5] Abdel-Jaber, M.S., "The Influence of Semi-Rigid Connections on the Behaviour of Beam and Column Structural System”, PhD Thesis: Oxford Brookes University, UK, 2002. 
[6] Sarawit, A.T. and Pekoz, T., "Design of Industrial Storage Racks", Proceedings sixteenth International Specialty Conference on Cold-Formed Steel Structures", Orlando, 2002, pp.369-384.

[7] Sarawit, A.T., "Cold-Formed Steel Frame and Beam-Column Design”, PhD Thesis: Cornell University, US, 2003.

[8] Freitas, A.M.S., Freitas, M.S.R. and Souza, F.T., "Analysis of Steel Storage Rack Columns", Journal of Constructional Steel Research, 2005, Vol. 61, No. 8, pp. 1135-1146.

[9] Beale, R.G., "The Influence of Semi-Rigid Connections on the Non-Linear Behaviour of Pallet Rack and Scaffold Structures". PhD Thesis: Oxford Brookes University, UK, 2004.

[10] Federation Europeéne de la Manutention, Section X, "Recommendations for the Design of Steel Pallet Racking and Shelving", 2000.

[11] The Rack Manufacturers' Institute, "Specification for the Design, Testing and Utilization of Industrial Steel Storage Racks", 1997.

[12] Beale, R.G. and Godley, M.H.R , "The Design of the Pallet Program", Proceedings of the sixteenth Specialty Conference on Cold-Formed Steel Structures, Orlando, 2002, pp.353-368.

[13] Beale, R.G. and Godley, M.H.R., "Developments in the Pallet Program", Advances in Structures, Sydney, 2003, pp. 237-243.

[14] Morz, K., Olsson, A. and Sandberg, G., "Parameter Studies on Pallet Racks", SP Swedish National Testing and Research Institute, SP Report 1998-2, 1998.

[15] Olsson, A. and Sandberg, G., "Reduction of Load Carrying Capacity in Pallet Racks due to Damaged Upright Beams", Tenth Nordic Seminar on Computational Mechanics, Tallinn, 1997, pp. 278-281.

[16] ABAQUS ANALYSIS User's Manual, Version 6.4, Hibbitt, Karlsson \& Sorensen, Inc., 2003. 